\title{
DETERMINING THE IMPACTS OF WILDFIRES ON PEAK FLOOD FLOWS IN HIGH MOUNTAIN WATERSHEDS
}

\author{
MOHAMMAD M. HASAN, STEVEN J. BURIAN \& MICHAEL E. BARBER \\ Department of Civil \& Environmental Engineering, University of Utah, Salt Lake City, Utah, USA
}

\begin{abstract}
Mountainous forested regions are the major sources of water for meeting downstream water demands in many parts of the world, including the United States, where two-thirds of the freshwater supply is estimated to originate from these areas. Wildfires pose significant threats to downstream urban infrastructure and livelihoods by impacting the timing, quantity and quality of waters emerging from these forested ecosystems. Wildfires affect key processes of the water cycle by reducing infiltration and interception, resulting in higher runoff volumes. Predicting post-fire flood events is important for proper water management and planning, including the safety of downstream communities. The objective of the study is to determine how changes in the locations of wildfire events coupled with the type (severity) of fire events affect peak flow regimes of high mountain watersheds. American Fork, a high mountain forest watershed in Utah with an area of 60 sq. miles $(155 \mathrm{sq} . \mathrm{km})$ and elevations ranging from 5,000 ft. to $11,700 \mathrm{ft}$. ( $1550 \mathrm{~m}$ to $3600 \mathrm{~m}$ ), is taken as the study area. A historical fire event that took place in a neighbouring watershed was superimposed on three different locations of the studying watershed with varying severity. A hydrologic model named Distributed Hydrologic Soil Vegetation Model was used to predict the flows due to changes in land cover and hydrologic processes for different wildfire events. Changes in peak flow due to different wildfire events at different locations of the watershed are analysed to estimate how location and type of wildfire events affect the peak flow regimes of the watershed and how thus it affects the overall downstream water supply. This study also identifies the critical location in the watershed for which the peak flow regime of the watershed will be most vulnerable due to a certain extent of wildfire.
\end{abstract}

Keywords: climate change, modelling, snowmelt, wildfire, sustainability, water planning and management.

\section{INTRODUCTION}

Maintaining good hydrologic conditions in high mountain forested watersheds is essential as these tributary areas are one of the major suppliers of freshwater in the world. Any forest disturbance affects the hydrologic cycle, including highly variable and complex temporal and spatial changes in snowmelt, runoff and peak flood flows. Among different types of disturbances, wildfire is the one which can significantly alter watershed conditions (DeBano et al. [1]). Wildfire is a dynamic process that can vary over time and landscape and can produce changes in hydrologic responses at different scales (Neary et al. [2]) depending on the extent, severity and intensity of the event. In addition to destroying vegetation, wildfires impact the biological, chemical and physical properties of soils due to the combustion of the organic matter present near the ground surface (Neary et al. [3]). Consequently, surface water runoff characteristics may be significantly altered.

Wildfire events in forested high mountain watershed areas with steep slopes and high fuel loads are significant natural disturbances as they can generate intense impacts on both runoff quantity and quality (DebAno et al. [1], Neary et al. [4]). Increases in the quantity of post-wildfire runoff and erosion events at the watershed scale are observed in the western United States (Benavides-Solorio and MacDonald [5]) as well as in Mediterranean Europe (Shakesby et al. [6], Cerda [7]) and South Africa (Fernquist and Floraberger [8]). Changes in vegetative cover and modification of soil properties of the watershed by wildfire may change the hydrology of the watershed in such a way that can alter post-wildfire runoff and erosion 
out of the range of historical variability. Increases in post-wildfire runoff and erosion, as well as its impact on the timing of peak runoff, may create severe threats to the downstream water distribution system, water quality, urban infrastructure and livelihoods.

Changes in the organic land cover, along with soil properties of the watershed due to wildfire, highly depend on the severity, intensity and extent of the wildfire. These changes eventually affect the key components of the hydrologic responses of a watershed like infiltration, interception and evapotranspiration. The location of wildfires also plays a dominant role, in combination with other factors, in influencing the quantity and timing of peak flows. Understanding the changes in watershed condition and hydrological responses of the watershed induced by the changes in severity, extent and location of the wildfire is essential to assess the potential effect of the fire event on many natural and cultural resources. The objective of the study is to determine how changes in the locations of wildfire events coupled with the type (severity) of fire affect the peak flow regimes of high mountain watersheds.

\section{BACKGROUND}

In the United States, high mountain forested area are the source of almost $60 \%$ of drinking water supply (Smith et al. [9], Stein et al. [10]) and the mountainous watersheds of the Wasatch mountain range in Utah are not an exception. Snow melting water coming through different streams from the Wasatch range provide about 50-60\% of the drinking water supply of Utah (Bardsley et al. [11]). From the year 2010 through 2017, there were 8,850 wildfire events recorded in Utah, burning a total of 972,790 acres of land according to the records of Utah statewide wildfire information (https://le.utah.gov/interim/2017/pdf/00003715.pdf). Out of these 8,850 events, the fire started naturally for almost $50 \%$ of cases burning about 500,000 acres of land. The locations of most of the naturally started fires were high mountain forested watersheds, which are the major sources of downstream water supply. The frequency of wildfire events as well as the land area burned by the wildfire is predicted to increase because of climate change in different studies (Dennison et al. [12], Hawbaker and Zhu [13]). The effects of wildfire on watersheds include increase runoff, hillslope erosion and stream sedimentation (Ryan and Noste [14], Meyer et al. [15]). Previous study has been conducted to find the impact of wildfire on stream runoff, erosion and water quality based on the frequency, severity and intensity of fire (Rhoades et al. [16], Sankey et al. [17]). One of the interesting subjects which has not been focused in previous wildfire studies is how the location of the wildfire on the high mountain watersheds effect stream runoff hydrograph. Understanding how the coupled effects of location and severity of a wildfire event in any mountainous watershed will affect the downstream water supply and distribution system is vital for the water managers, planners and decision makers for future planning. In this study, we will examine how the location of wildfire events, in combination with varying fire severity, affects the timing and intensity of peak flow in mountainous watersheds.

\subsection{Study Area}

The study area is the American Fork watershed, which lies in Utah County, Utah, southeast of Salt Lake City, and a part of the Wasatch Mountains (Fig. 1). American Fork watershed has an area of about 60 square miles (155 square $\mathrm{km}$ ), with the elevation ranges from 5,000 to $11,700 \mathrm{ft}$. (1550 to $3600 \mathrm{~m}$ ). Most of the watershed has slopes varying from 10 to 30 degrees, but a small part of the watershed has steep slopes varying from 40 to 71 degrees. 


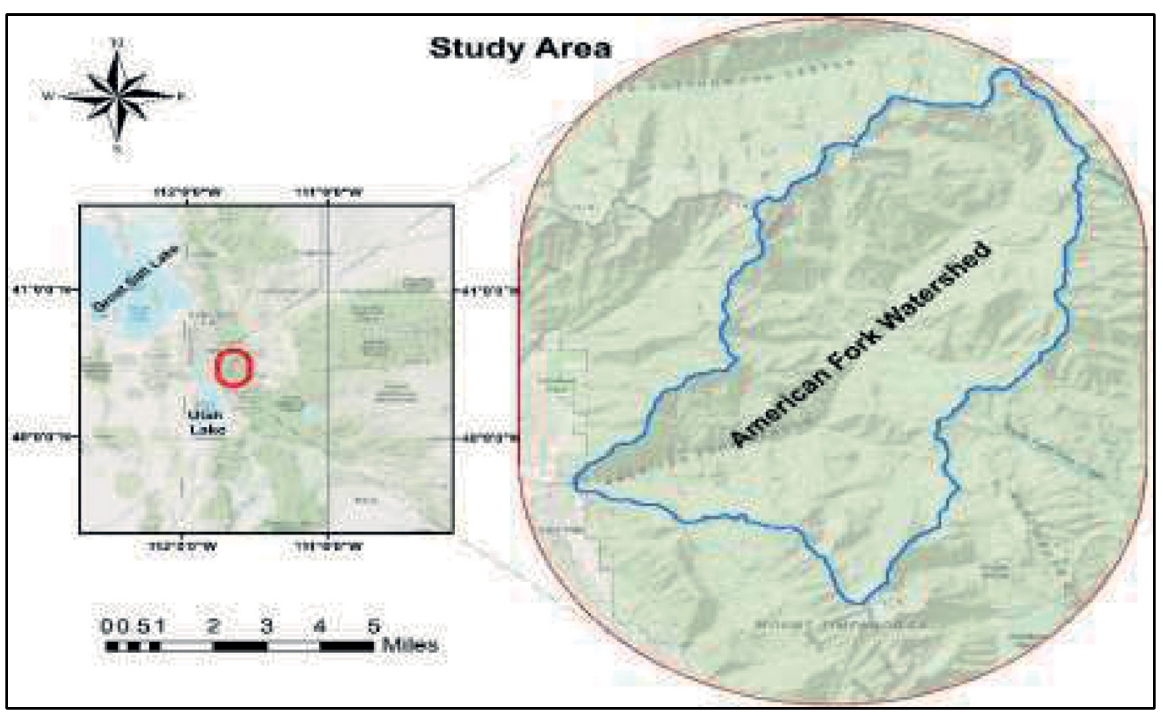

Figure 1: American Fork watershed.

This watershed is recoded as one of the major sources of irrigation water by the Department of Water Quality, Utah.

Nine types of vegetation are found in the study area according to the National Land Cover Database (NLCD) 2011 map of which the most dominant vegetation types are coastal conifer, closed shrubs, deciduous forest and grassland. With reference to the State Soil Geographic Database (STATSGO2) soil database, silt loam and cobbly clay loam are the two most dominant types out of four types of soil available in the watershed.

\section{MOTIVATION AND AIM}

Fire severity, size, frequency, intensity, seasonality and type make up the six components of a fire regime (Flannigan et al. [18]). Although climate change has been shown to affect all of these components (Abatzoglou and Williams [19]), this study focused on the severity and spatial extent (size and location).

Fire severity is the common term used to describe the relative magnitude of the post-fire disturbance. Uniform and consistent definitions for fire severity are impossible to find in the literature due to the unique nature of each fire (physical setting, fuel load and weather conditions) and variation in intensity across the burn area (Jain and Graham [20]). In a study involving several western states including Utah, U.S. Forest Service foresters developed the sixlevel system for soil and tree burn severity shown in Table 1. Even within each of these levels, the potential for highly variable conditions exists as a result of a myriad of factors impacting ecosystem responses (Keeley [21]). As comprehensive prediction of fires was beyond the scope of this project, the complexity of wildfires on land cover characteristics was simplified for the purpose of this study. The modelling assumptions used are shown in Table 1.

Runoff implications couple changes in imperviousness with changes in the size of the disturbance. The size of the area burned is dependent on numerous factors, although two major causes are fuel aridity and increased continuity of fuels due to activities such as fire 
Table 1: Fire severity classifications in post-fire environments.

\begin{tabular}{lll}
\hline Level & Condition Description & Modelling Assumptions \\
\hline 1 & $>85 \%$ litter cover & No change in cover \\
2 & $40-85 \%$ litter cover & $\begin{array}{l}40 \% \text { reduction in land surface perviousness } \\
\text { in burn areas }\end{array}$ \\
3 & $5-40 \%$ litter with black char & $\begin{array}{l}75 \% \text { reduction in land surface perviousness } \\
4\end{array}$ \\
$5-40 \%$ litter with white or grey char & in burn areas \\
6 & $0-5 \%$ litter with black char & The impervious area throughout burn areas \\
6 & $0-5 \%$ litter with white or grey char & \\
\hline
\end{tabular}

suppression, logging and grazing (Cansler and McKenzie [22]). A recent study for the western United States concluded that climate change-induced fuel aridity has led to significant increases in forest fire area (Abatzoglou and Williams [19]).

\section{METHODOLOGY}

For this study, we choose a wildfire event that took place in a neighbouring canyon, which has the same types of vegetation and soil, and having almost the same size, and elevation of the studying watershed. The wildfire event took place in 2016, and the size of the fire was about 7 square miles (4,700 acres), almost $11 \%$ of the total study area. In this study, we superimpose that fire event in three different locations of the watershed, coupled with three different types of fire severity.

\subsection{Scenario development}

Based on the location and the severity of the wildfire event, nine scenarios were developed for this study (Table 2).

\subsection{Location of wildfire and severity classification}

Three locations within the watershed based on elevation were chosen on a random basis to superimpose the wildfire event (Fig. 2). Table 3 explains the range of elevation of the three locations.

Fire disturbance impact on vegetation depends on the different types of burn severity and is addressed by changing the vegetation properties following a wide range of logics. Using the reclassify tool in ArcMap 10.4.1, the vegetation grids of the burned area were reclassified to represent the respective burn severity using the following logical assertions in Distributed Hydrologic Soil Vegetation Model (DHSVM).

All burned grids kept the same designation with an addition of the type of burn severity before it. For example, any grid of the deciduous forest group affected by low severity burn was reclassified as low severity deciduous forest. Grids affected by high severity wildfire were reclassified as burned bare ground irrespective of vegetation types. We assume burned bare ground possess the same vegetative characteristics as unburned barren land.

Watershed grids affected by medium severity wildfire and classified as a vegetation class having both understory and overstory forest canopies were reclassified to represent a complete 
Table 2: Scenario matrix based on the severity and location of the wildfire.

\begin{tabular}{llll}
\hline Watershed Location & \multicolumn{3}{c}{ Wildfire Severity } \\
\cline { 2 - 4 } & Low & Medium & High \\
\hline Lower & Lower Elevation - & Lower Elevation - & Lower Elevation - \\
& Low Severity & Medium Severity & High Severity \\
Middle & Middle Elevation - & Middle Elevation - & Middle Elevation - \\
& Low Severity & Medium Severity & High Severity \\
Upper & Upper Elevation - & Upper Elevation - & Upper Elevation - \\
& Low Severity & Medium Severity & High Severity \\
\hline
\end{tabular}

Table 3: Range of elevation of the wildfire locations.

\begin{tabular}{ll}
\hline Watershed Location & Elevation Range $(\mathrm{ft})$ \\
\hline Lower & $5,564-10,000$ \\
Middle & $6,364-10,252$ \\
Upper & $7,076-10,662$ \\
\hline
\end{tabular}

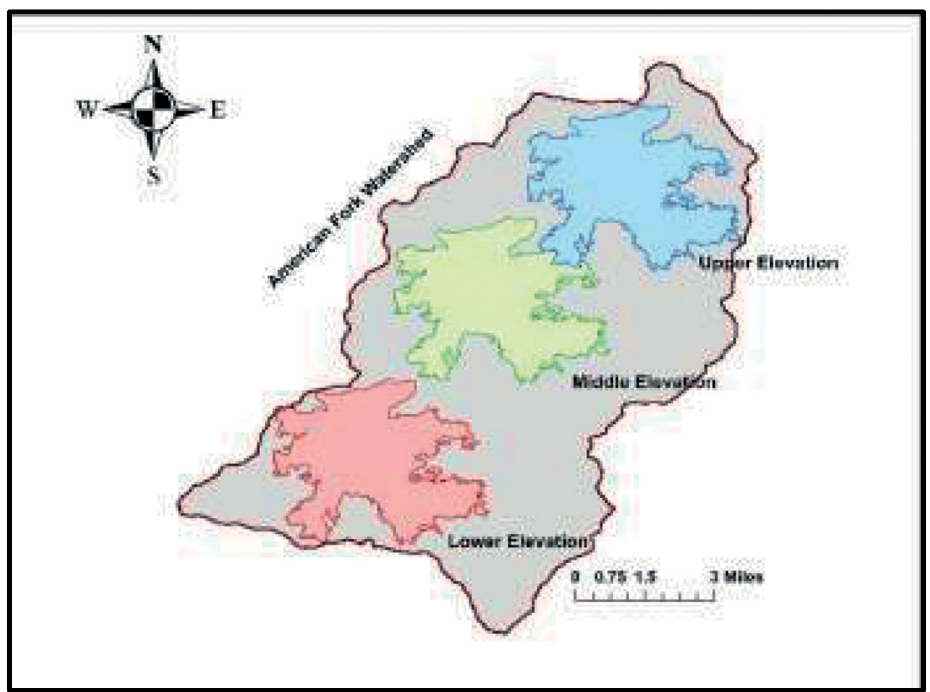

Figure 2: Locations of the wildfire event.

removal of understory and 50\% reduction in overstory leaf area index (LAI) in addition to $50 \%$ reduction in fractional coverage and snow interception efficiency. Grids affected by a medium severity fire behaviour and classified as shrublands were reclassified to represent a $70 \%$ reduction in monthly LAI and a 50\% reduction in fractional coverage.

All grids affected by low severity burns and classified as a vegetation type having both overstory and understory forest canopies were reclassified to represent a complete removal of 
understory and undisturbed overstory. Grids affected by a low severity burn and classified as shrublands were reclassified to represent a $35 \%$ reduction in monthly LAI and a $25 \%$ reduction in fractional coverage. Grids affected by low or medium severity burn and classified as grassland, pasture/hay or cropland were reclassified as burned bare ground.

Reclassification of soils of the burned area under different types of burn severity was done using the same reclassify tool of ArcMap 10.4.1. The following assumptions were made to represent the characteristics of different types of burned severity soil in DHSVM.

- All burned grids of the soil map retained the previous pre-burn designation with the addition of the type of burn severity before it.

- The infiltration capacity of the soil grids, which experienced high severity burn behaviour, was reduced to zero or no infiltration irrespective of soil class.

- Soil grids affected by medium severity wildfire were reclassified to represent a $75 \%$ reduction in infiltration capacity.

- Grids affected by a low severity fire behaviour were reclassified to represent a $40 \%$ reduction in infiltration capacity.

\subsection{Distributed Hydrologic Soil Vegetation Model}

The physically based DHSVM was selected for this study. DHSVM provides a dynamic representation of watershed processes taking into consideration the effects of topography, soil and vegetation while solving the energy and water balances at each grid cell at each timestep (Wigmosta et al. [23]). DHSVM is a highly complex model suitable for a wide range of watershed hydrology applications involving streamflow prediction (Beckers et al. [24]). The model has been widely used in studying mountainous watersheds up to approximately $100,000 \mathrm{~km}^{2}$ in size. Hydro-climatic inputs are near surface meteorology which includes air temperature, wind speed, humidity, precipitation and incoming short- and longwave radiation. Model outputs may be generated on sub-daily timescales for multi-year simulation periods.

\subsection{Hydrologic model, data and running time}

A physically based hydrologic model was developed using DHSVM for the studying watershed. This model was well-calibrated for the duration of 01 October 1998 to 30 September 2004 at hourly temporal resolution. All the hydro-climatic input used in the calibration process was at an hourly temporal resolution, and all land surface data used in the calibration process were at $30 \mathrm{~m}$ spatial resolution. The observed historical runoff data of the stream was collected from the respective USGS stream gauge (USGS 10164500).

In this study, we used vegetation type, soil type, digital elevation model, soil depth and flow direction map of the studying watershed, each with the same $30 \mathrm{~m}$ spatial resolution and same extent (Fig. 3). Hydro-climatic inputs used in this study were collected from Multivariate Adaptive Constructed Analogs statistically downscaled historical baseline scenario for three different time periods of WY 2005 (01 October 2004 to 30 September 2005) to get an understanding of the consequences of wildfire of different types of severity at different locations in the watershed on runoff. The calibrated hydrologic model was run at an hourly temporal resolution with a spin-up period of 9 months for each scenario that 


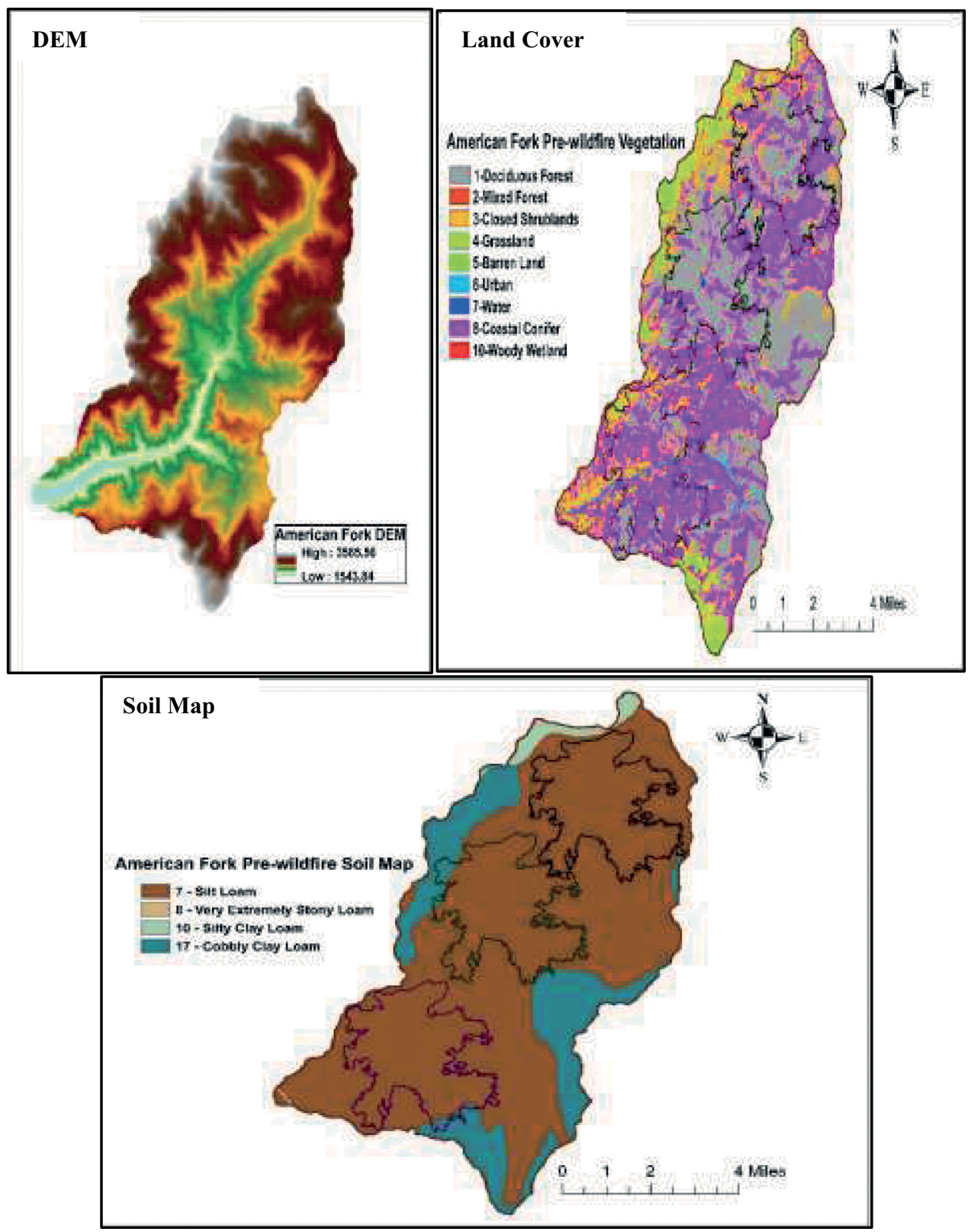

Figure 3: Spatial inputs to the DHSVM pre-wildfire scenario.

was developed based on the location and severity of fire (Table 2). Hydro-climatic inputs of the model were changed to run the model for different time periods, whereas the spatial inputs of the models were changed when there was a change in location and severity of the wildfire event. 


\section{RESULTS AND DISCUSSION}

The hydrologic models generated time-series outputs of hourly stream runoff at the outlet of the watershed for different scenarios. The model's simulated hourly stream runoff outputs were aggregated to average daily runoff using a self-developed R-code. We examined the response of the watershed based on the location of the fire, that is, how the watershed hydrologically responds for a particular type of fire at the lower, middle and upper elevation of the watershed. Each model was run for the entire period of a particular water year (01 October through 30 September), although the results presented in this article are for the period of 01 April to 30 September. The reason for this is that no significant variations in flow were found during the off-peak season for any scenario thus shortening the period of analysis allows better graphical representation of the results.

\subsection{High severity wildfire at different locations}

In WY 2005, the American Fork watershed, on average, received approximate 63.8 inches $(1,620 \mathrm{~mm})$ of precipitation. The effect of a high severity wildfire due to change in the location of the wildfire on stream runoff is quite significant (Fig. 4). Peaks shown in Fig. 4 from April to mid-May for the high severity fire at the lower, middle and upper elevations were mainly due to several small to medium individual precipitation events at that time. In the case of the pre-wildfire period, water generated from those rain events were infiltrated and evaporated in such a way that no extra water was coming to the stream.

The high severity fire at the lower elevation scenario generated a higher runoff volume and earlier peak flow for the small individual precipitation event compared to the location of the fire at the middle or upper elevation. The reason is because of the high severity fire, there were some changes in vegetation and soil infiltration, which affect the timing and amount of runoff. At lower elevation, those precipitation events were mostly rainfall, and the travel time was relatively short. Soil and vegetation characteristics were changed based on fire severity. All three locations have experienced similar changes in soil and vegetation because of particular fire severity. But the nature and quantity of precipitation varied with elevation which resulted in changes in runoff volumes and the timing of peak flows. Fire in the middle elevation caused earlier peak flows than the upper and lower elevation. The fire in upper elevation generated a higher volume of runoff than the middle elevation for those small to medium individual rainfall events.

During peak runoff season (May and June), fire events in the middle elevation region created the highest runoff volumes and earliest peaks compared to the pre-wildfire runoff hydrographs. The same fire events at the lower elevation showed no significant changes in runoff volumes and only slightly earlier peaks.

An enlarged view of the red circled part shown in Fig. 4 (bottom figure) illustrates that although there are some smaller peaks in the post-wildfire runoff due to rainfall events occurring from mid-July to September, the overall baseflow is lower than pre-wildfire baseflow during that time. Lower baseflows during the dry season caused by reduced infiltration indicate low flow events that will cause additional issues during drought years. 


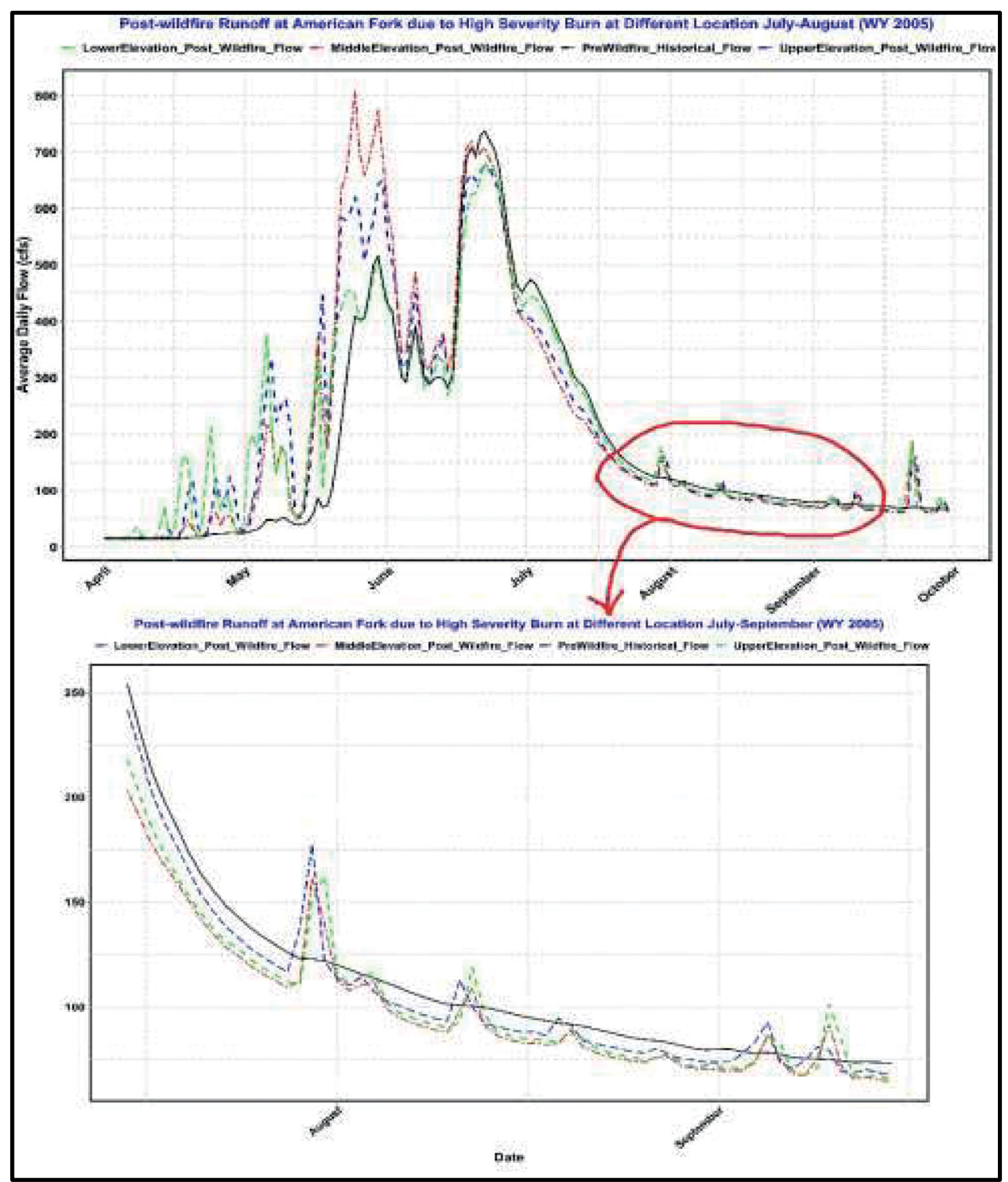

Figure 4: Post-wildfire runoff due to high severity wildfire at different elevations.

\subsection{Medium severity wildfire at different locations}

The changes in runoff hydrograph due to a medium severity wildfire at different locations in the watershed (Fig. 5) are different from the high severity wildfire event. Dry season postwildfire flows are almost the same as the pre-wildfire flow. Rainfall events between April to mid-May and mid-July to September do not generate any peak flows within this period. 


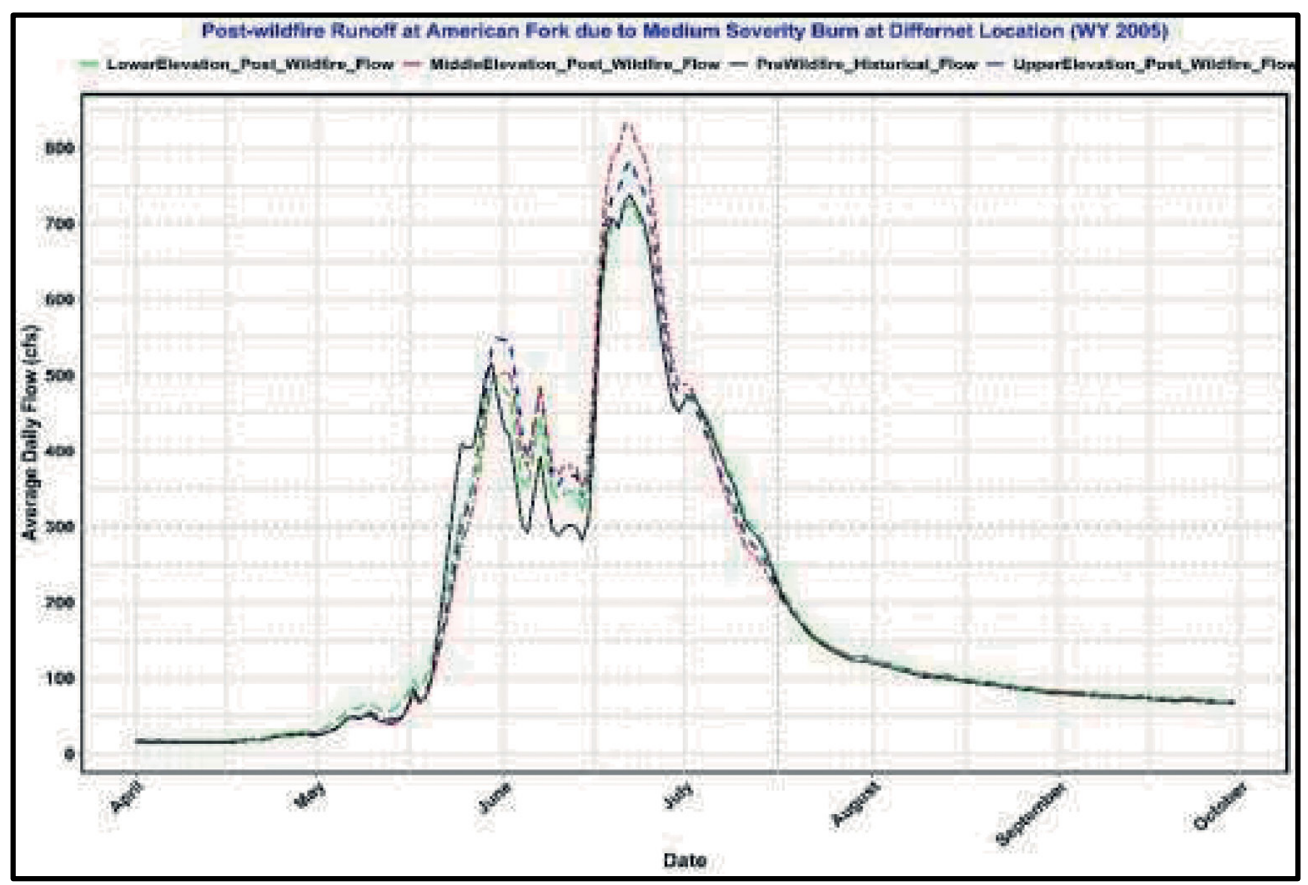

Figure 5: Post-wildfire runoff due to medium severity wildfire at different elevations.

A moderate increase in peak flows with no significant change in timing for the fire event at medium and upper elevation whereas no significant change in the runoff for the fire event at the lower elevation.

\subsection{Low severity wildfire at different locations}

A low severity fire event does not have any significant impacts on the annual stream runoff regardless of its location. Figure 6 shows the post-wildfire runoff hydrograph for all three locations, including the pre-wildfire runoff hydrograph. There is no significant change in timing and magnitude of peak flow as well as dry season baseflow between pre- and postwildfire runoff.

This study is important to understand how a watershed will respond after a wildfire event based on the severity and location of the fire. For example, a high severity fire in middle elevation can generate a flood in the peak season as well as can cause drought or shortage of water supply in the dry season. This understanding will help decision makers, planners and water managers to plan adequately for water supply, storage and distribution after a wildfire event.

Changes in spring snowmelt are closely related to overstory LAI. A complete reduction of overstory LAI due to high severity fire not only increases snow accumulation during winter but also reduces canopy attenuation both of which can increase the peak runoff. Furthermore, this study shows that the location of wildfire has a significant influence on the intensity and timing of peak runoff. This study assumes a uniform severity fire event for the whole burned area in each scenario which can differ in reality. The results of this study can vary with the changing combinations of watershed's physical properties (like slope, aspect), vegetative cover, soil map and climate. 


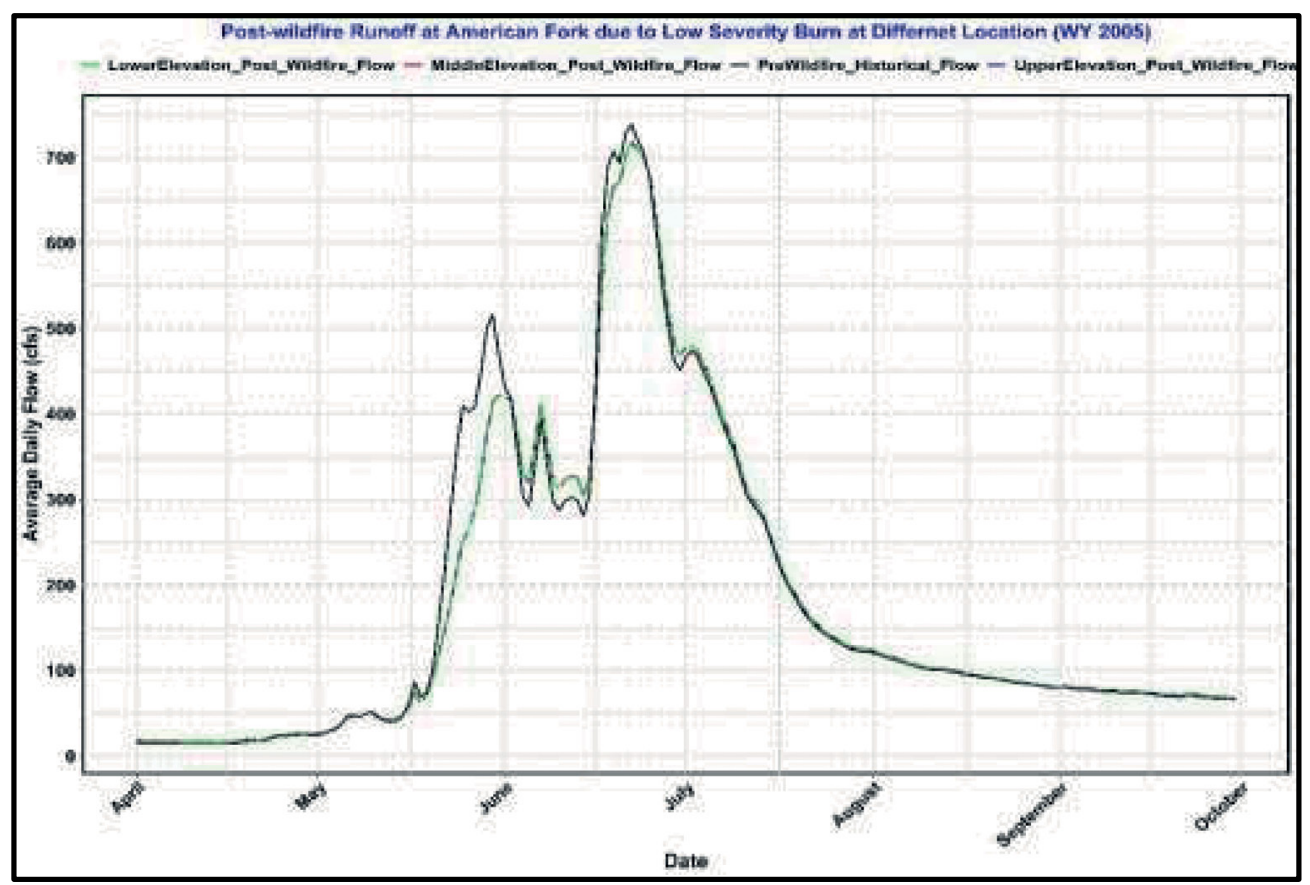

Figure 6: Post-wildfire runoff due to low severity wildfire at different elevations.

\section{CONCLUSIONS AND RECOMMENDATIONS}

Wildfire events are rising not only in numbers but also in size, intensity and severity all over the world. Understanding the post-fire hydrologic responses of watersheds in terms of variation in intensity and timing of peak flow depending on the location of the wildfire is vital for effective risk management and mitigation of post-fire hydrologic hazards. This hypothetical study shows significant variations in annual stream runoff for high severity wildfires at the lower, middle and upper elevations. For a high severity fire at the lower elevation, small and medium individual storms can generate almost twice as much as flow than a high severity flow in the middle elevation, mainly due to rapid snow melting in the lower watershed. During the peak flow period, a high severity fire at middle elevation generates about $24 \%$ and $58 \%$ higher runoff than the same fire event can generate in high and low elevation, respectively. The timing of the peak runoff is 3-5 days earlier due to a fire event in the middle elevation compare to the same fire event in the high and low elevation, respectively. A high severity fire at high elevation generates $27 \%$ higher peak runoff than the fire event in the lower elevation. The increase in peak runoff due to the fire event in the middle and high elevation increases the downstream flood potential.

Small to medium intensity peak flows were generated due to individual rainfall events during the off-peak season after a high severity wildfire at different locations. Overall, however, base flows were $12-15 \%$ less after severe fire events indicating possible concerns over ecological flows particularly during drought conditions. These trends in low flows after high severity fire events occurred regardless of the location of the fire, but the lowest base flow has found for the fire event at the middle elevation. No significant changes in annual runoff hydrograph were found for a low severity fire at any location. Low and medium severity fire 
events do not affect the base flow significantly. The watershed was found to be most vulnerable for a high severity fire at the middle elevation in terms of both timing and intensity of peak runoff and low flow period.

\section{ACKNOWLEDGEMENTS}

This article was developed under Assistance Agreement No. 83586601 awarded by the U.S. Environmental Protection Agency to the University of Utah. It has not been formally reviewed by EPA. The views expressed in this document are solely those of the authors and do not necessarily reflect those of the Agency. EPA does not endorse any products or commercial services mentioned in this publication.

\section{REFERENCES}

[1] DeBano, L.F., Neary, D.G. \& Ffolliott, P.F., Fire's Effects on Ecosystems. John Wiley \& Sons, Inc.: New York, pp. 333, 1998.

[2] Neary, D.G., Koestner, K.A. \& Youberg, A., Hydrologic impacts of high severity wildfire: learning from the past and preparing for the future. Presented at the 24th Annual Symposium of the Arizona Hydrological Society, Flagstaff, Arizona, 2011.

[3] Neary, D.G., Ryan, K.C. \& DeBano, L.F., Wildland fire in ecosystems: effects of fire on soils and water. U.S. Department of Agriculture, Forest Service, Rocky Mountain Research Station, General Technical Report, 4, pp. 250, 2008.

[4] Neary, D.G., Klopatek, C.C., DeBano, L.F. \& Ffolliott, P.F., Fire effects on belowground sustainability: a review and synthesis. Forest Ecology and Management, 122, pp. 51-71, 1999.

[5] Benavides-Solorio, J. \& MacDonald, L. H., Post-fire runoff and erosion from simulated rainfall on small plots, Colorado Front Range. Hydrological Processes, 15, pp. 29312952, 2001.

[6] Shakesby, R.A., Coelho, C.O.A., Ferreira, A.D., Terry, J.P. \& Walsh, R. P. D., Wildfire impacts on soil erosion and hydrology in wet Mediterranean forest, Portugal. International Journal of Wildland Fire, 3, pp. 95-110, 1993.

[7] Cerda, A., Changes in Overland flow and infiltration after a rangeland fire in a Mediterranean scrubland. Hydrological Processes, 12, pp.1031-1042, 1998.

[8] Fernquist, J. \& Floraberger, I., Fire and post-fire soil erosion in Western Cape, South Africa: field observation and management practices. Unpublished, Committee of Tropical Ecology, Uppsala University, Sweden, 2003.

[9] Smith, H.G., Sheridan, G.J., Lane, P.N.J.J., Nyman, P. \& Haydon, S. Wildfire effects on water quality in forest catchments: a review with implications for water supply. Journal of Hydrology, 396, pp. 170-192, 2011.

[10] Stein, S.M., McRoberts, R.E., Alig, R.J., Nelson, M.D., Theobald, D.M., Eley, M., Dechter, M. \& Carr, M. Forests on the edge: housing development on America's private forests. USDA Forest Service General Technical Report, 1-16, 2005.

[11] Bardsley, T., Wood, A., Hobbins, M., Kirkham, T., Briefer, L., Niermeyer, J. \& Burian, S. Planning for an uncertain future: climate change sensitivity assessment toward adaptation planning for public water supply. Earth Interactions, 17(23), pp. 1-26, 2013.

[12] Dennison, P.E., Brewer, S.C., Arnold, J.D. \& Moritz, M.A. Large wildfire trends in the western United States 1984-2011. Geophysical Research Letters, 41, pp. 2928-2933, 2014. 
[13] Hawbaker, T. J. \& Zhu, Z. Projected future wildland fires and emissions for the Western United States, in Baseline and Projected Future Carbon Storage and Greenhouse-Gas Fluxes in Ecosystems of the Western United States. U.S. Geological Survey Professional Paper 1797, pp. 97-108, 2012a.

[14] Ryan, K.C. \& Noste, N.V. Evaluating prescribed fires. In: J.E. Lotan, B.M., Kilgore, W.C. Fischer, and R.W. Mutch (Tech. Coords.) Proceedings, Symposium, and Workshop on Wilderness Fire. U.S. Forest Service, Ogden, Utah, pp. 230-238, 1983.

[15] Meyer, G.A., Wells, S.G. \& Jull, A.J.T. Fire and alluvial chronology in Yellowstone National Park: climatic and intrinsic controls on Holocene geomorphic processes. Geological Society of America Bulletin, 107, pp. 1211-1230, 1995.

[16] Rhoades, C.C., Chow, A.T., Covino, T.P., Fegel, T.S., Pierson, D.N. \& Rhea, A.E. The legacy of a severe wildfire on stream nitrogen and carbon in headwater catchments. Ecosystems, 22, pp. 643-657, 2019.

[17] Sankey, J. B., Kreitler, J., Hawbaker, T. J., McVay, J. L., Miller, M. E., Mueller, E. R., Nicole, M.V., Scott, E.L. \& Sankey, T. T. Climate, wildfire, and erosion ensemble foretells more sediment in western USA watersheds. Geophysical Research Letters, 44(17), pp. 8884-8892, 2017. https://doi.org/10.1002/2017GL073979.

[18] Flannigan, M.D., Stocks, B.J. \& Wotton, B.M., Climate change and forest fires. Science of the Total Environment, 262(3), pp. 221-229, 2000.

[19] Abatzoglou, J.T. \& Williams, P., Impact of anthropogenic climate change on wildfire across western U.S. forests. Proceedings of the National Academy of Sciences, 113(42), 11770-11775, 2016.

[20] Jain, T.B. \& Graham, R.T., The relation between tree burn severity and forest structure in the Rocky Mountains. USDA Forest Service General Technical Report PSWGTR-203, 2007.

[21] Keeley, J.E., Fire intensity, fire severity and burn severity: a brief review and suggested usage. International Journal of Wildland Fire, 18, pp. 116-126, 2009.

[22] Cansler, C.A. \& McKenzie, D., Climate, fire size, and biophysical setting control fire severity and spatial pattern in the northern Cascade Range, USA. Ecological Applications, 24(5), pp. 1037-1056, 2014.

[23] Wigmosta, M.S., Vail, L.W. \& Lettenmaier, D.P., A distributed hydrology soil vegetation model for complex terrain. Water Resources Research, 30(6), pp. 1665-1679, 1994.

[24] Beckers, J., Smerdon, B., Redding, T., Anderson, A., Pike, R. \& Werner, A.T., Hydrologic models for forest management applications. Part 1: model selection. Streamline Watershed Management Bulletin, 13, pp. 35-44, 2009. 